\title{
ОСОБЕННОСТИ УГЛЕВОДНОГО ОБМЕНА У ДЕТЕЙ ПОДРОСТКОВОГО ВОЗРАСТА С НАРУШЕННЫМ РАСПОЗНАВАНИЕМ ГИПОГЛИКЕМИИ ПРИ ИСПОЛЬЗОВАНИИ РАЗЛИЧНЫХ СИСТЕМ МОНИТОРИРОВАНИЯ ГЛИКЕМИИ
}

\author{
Демяненко А.Н., Алимова И.Л. \\ ФГБОУ ВО «Смоленский государственный медицинский университет» МЗ РФ, Смоленск
}

ЦЕЛЬ: изучить особенности углеводного обмена у детей подросткового возраста с нарушенным распознаванием гипогликемии по данным непрерывного мониторирования глюкозы.

МАТЕРИАЛЫ И МЕТОДЫ: обследовано 36 детей подросткового возраста с сахарным диабетом 1 типа (СД1), находящихся на режиме многократных инъекций инсулина (Аспарт, Деглюдек) с анкетированием по методу Clarke (4 балла и более свидетельствовали о нарушенном распознавании гипогликемии (НРГ)) и мониторированием гликемии (НМГ). НМГ исходно проводилось в «слепом» режиме (i-Pro2) и в динамике через 6-9 месяцев с применением флеш-мониторинга (FreeStyle Libre). Статистическая обработка проводилась с помощью программы Statistica 7.0 (StatSoft 2009).

РЕЗУЛЬтАТЫ: возраст пациентов на момент первичного обследования составил 14,5 лет [12,0-16,0], длительность диабета-5,0 лет [3,0-6,3], уровень $\mathrm{HbA}_{1 c}-8,7 \%$ [7,8-10,5]. По Clarke НРГ было диагностировано у 8(22\%) детей подросткового возраста, больных СД1. Пациенты с НРГ и без НРГ были сопоставимы ( $>0,05)$ по возрасту, полу, длительности сахарного диабета, уровню $\mathrm{HbA}_{1 c^{\prime}}$ частоте хронических осложнений. При первичном обследовании по данным і-Pro2 пациенты с НРГ в сравнении с пациентами без НРГ $(p<0,05)$ дольше находились в гипогликемии (8\% [4-15] и 2\% [0-6] соответственно), у них отмечалось больше эпизодов ночных гипогликемий (6 [3-10] и 1 [0-4], p<0,05) с большей длительностью (80мин [25-136] и 35мин [10-65]), в том числе 6 эпизодов пролонгированных (более 120 минут) бессимтомных ночных гипогликемий. По времени в целевом диапазоне (39\% [23-64] и 22\% [18-48]) и времени выше целевого диапазона (44\% [34-68] и 54\% [47-78]) различий между группами не получено.

Всем пациентам с НРГ было рекомендовано использование флеш-мониторирования глюкозы. Через 6-9 месяцев все пациенты с НРГ вновь были опрошены по Clarke, НРГ было подтверждено у 4 из 8. Однако по результатам флеш-мониторинга гликемии у них зарегистрировано $(p<0,05)$ уменьшение времени гипогликемии (3\% [0-12]), длительности (46 мин [22-98]) и частоты эпизодов ночной гипогликемии (2 [0-4]), отсутствие пролонгированных гипогликемий и увеличение продолжительности времени выше целевого диапазона (68\% [53-78]) в сравнении с результатами предыдущего мониторинга (i-Pro2). Различий по времени в целевом диапазоне (36\% [28-56]) и уровню $\mathrm{HbA}_{1 c} 8,5 \%$ [7,2-10,1] не получено. Другими словами, уменьшение гипогликемий по частоте и длительности сопровождалось увеличением времени пребывания в диапазоне выше целевого уровня. При индивидуальном анализе у пациентов с сохранившимся синдромом НРГ длительность использования флеш-мониторирования глюкозы составила 1,5месяца $[1,0-2,3]$, у пациентов с восстановленной чувствительностью к гипогликемии-3,6месяца $[3,1-4,0](p<0,05)$. У пациентов без НРГ в динамике по данным флеш-мониторирования отмечено увеличение времени в целевом диапазоне (42\% [25-75],p<0,05), а время выше целевого диапазона (43\% [30-62]) и время ниже целевого диапазона (1\% [0-2]) в динамике не различались (p>0,05).

ВЫвОды: использование непрерывного мониторирования глюкозы в течение более 3-х месяцев у пациентов с нарушенным распознаванием гипогликемии сопровождается уменьшением времени и длительности гипогликемии, частоты эпизодов ночной и пролонгированной гипогликемии при увеличении времени выше целевого диапазона и стабильных показателях $\mathrm{HbA}_{1 c}$.

КЛЮЧЕВЫЕ СЛОВА: сахарный диабет; нарушенное распознавание гипогликемии; дети; мониторинг гликемии. 